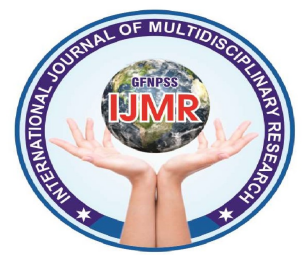

\title{
A STUDY TO ASSESS THE OPINION AMONG B.SC NURSING STUDENTS REGARDING CLINICAL SUPERVISION BY SUPERVISOR IN SELECTED HOSPITALS OF PUNJAB
}

\author{
SANDEEP KAUR, SUPRIYA, SHRUTI SHARMA,VINAYPAL BHULLAR \\ SUKHMANPREET KAUR, NAVNEET KAUR, SUKHMANPREET KAUR ${ }^{1}$ SANJAY $^{-}$ \\ KUMAR GUPTA ${ }^{2}$ HARPREET KAUR ${ }^{3}$ \\ ${ }^{1}$ B.Sc.Nursing students SINPMS, Badal, (Punjab) \\ ${ }^{2}$ Assistant Professor \& HOD (Community Health Nursing), State Institute of Nursing \\ \& Para Medical Sciences, Badal (Punjab) A constituent college of BFUHS, Faridkot \\ ${ }^{3}$ Nursing demonstrator, SINPMS, Badal \\ Corresponding Email: ssanjunurse@yahoo.co.in
}

\begin{abstract}
Background:- Clinical supervision plays a major role in the undergraduate nursing programme. These have been some local studies addressing clinical supervision; however, these still remains a lack of knowledge and understanding how to improve quality supervision of undergraduate nursing students.
\end{abstract}

Aim of the study: The aim of the study is to assess the opinion among B.Sc. Nursing students regarding clinical supervision by supervisor in selected hospital, Punjab.

Material and method:-A Quantitative research approach a study in which descriptive research design was used to conduct the research study. 100 Nursing students of University College of Nursing, Faridkot were selected for study with purposive sampling technique. A self structured questionnaire was used to assess the opinion among B.Sc. Nursing students regarding clinical supervision by supervisor.

Result :-The study depicted revels that out of 100 nursing students of 64(64\%), students have strongly agree opinion, 24(24\%) have agree opinion, $12(12 \%)$ have disagree opinion regarding clinical supervision by supervisor. So majority of Nursing students have strongly agree opinion regarding clinical supervision by supervisor. The overall mean and S.D is 51 and 17.5. Level of opinion was significantly $(p<0.05)$ not associated with age, gender, class, duration of clinical experience, current status of residence, number of wards you experienced. Conclusion:-The researcher concluded that majority of B.Sc. Nursing students had strongly agree opinion regarding clinical supervision by supervisor. Clinical supervision plays a major role in the undergraduate nursing programme. These have been some local studies addressing CS; however, these still remains a lack of knowledge and understanding how to improve quality supervision of undergraduate nursing students.

KEY WORDS: Opinion, Nursing students, clinical supervision, supervisor. 


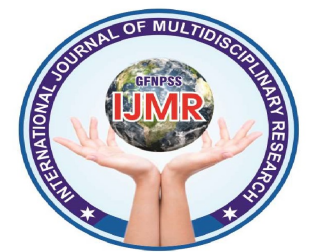

\section{INTRODUCTION}

Supervision is an integral part of each and every study. As a work without any supervisory authority or any observance goes unproductive. Here the research study revolves around the concept of supervision among B.Sc. Nursing Students as Bachelor of science Nursing (BSN) students education comprises a theoretical and a practical part. Both these aspects includes supervision as well as systematic reflection on the learning situation clinical supervision refers to the professional entering into the relationship with practical situation and having the confidence to enter into an equal partnership with other health care professionals in their guest to make a real contribution to health and health care.

Supervision plays a major role in clinical area to attain clinical experience, skills and knowledge enhancement. Clinical Supervision provides a safe environment for clinician to actively engage with each other to reflect on their clinical practice and improve standard of care. It allowed them to think proactively and find solution to problem, example, dealing with difficult situations or conflict. Many of professional issues we face can be challenging and overwhelming, but being able to discuss these with peers can only enhance practice and individuals understanding of these to ultimately benefit practice in the wider context. The process of supervision facilitates the individual to develop knowledge and competence, and link theory and research to practice

\section{OBJECTIVES}

- To assess the opinion of B.Sc. Nursing students regarding clinical supervision by supervisor.

- To find out the association of clinical supervision by supervisor with selected demographic variables.

\section{MATERIAL AND METHODS}

A non experimental research approach was used that is considered to be appropriate for the present study in order to assess the opinion of Nursing students regarding clinical supervision A descriptive research design was considered appropriate for the present study to assess the opinion of Nursing students regarding clinical supervision with demographic variables like Age, Gender, Class, Duration of clinical experience, Current status of residence, Number of wards you experienced. Dependent variables of the study was opinion of Nursing students regarding clinical supervision The study was conducted in University 


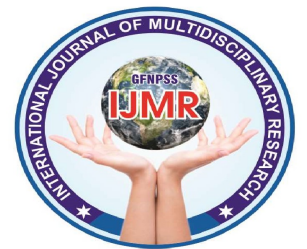

Original Article

college of Nursing, Faridkot, Punjab. The total nursing students in were 250. The target population of this study was the nursing students in University college of nursing, faridkot 100 nursing students were selected as sample on the basis of convenience sampling technique from nursing college who were fulfilling the inclusion criteria. For data collection tools were prepared after extensive review of literature and with the help of experts, having following sections: Section A: Description of Demographic Variables.

Section B: Self structured questionnaire related to opinion regarding clinical supervision.

\section{RESULTS}

Sample characteristics as per age majority of nursing students maximum $69(69 \%)$ students were in the age group of 21 or more and minimum 4(4\%) students were in age group of 18 year followed by $17(17 \%)$ students were in age group of 20 years. Distribution of subjects according to gender maximum 92(92\%) students were from female gender and minimum $8(8 \%)$ students were from male gender. As per class, students of B.Sc Nursing $2^{\text {nd }}$ year $50(50 \%)$ and students from B.Sc. nursing $4^{\text {th }}$ year is $50(50 \%)$ having same. According to duration of clinical experience, maximum 69(69\%) having more than 1 year experience and 2-3 months and 4-6 months having same percentage i.e. $7(7 \%)$ followed by $17(17 \%)$ students having 7-9 months clinical experience. According to current status of residence, maximum $77(77 \%)$ are hostlers and minimum 23(23\%) are non hostlers. According to Number of wards you experienced, maximum 45(45\%) are 6 or more wards and minimum 15(15\%) are 2-3 wards, followed by $40(40 \%)$ are $4-5$ wards.

Table 1: Frequency and percentage distribution of nursing students depending upon their opinion regarding clinical supervision by supervisor

$\mathbf{N}=\mathbf{1 0 0}$

\begin{tabular}{|c|c|c|c|}
\hline Levels & Range & Frequency & Percentage \\
\hline $\begin{array}{c}\text { Strongly } \\
\text { agree }\end{array}$ & $51-75$ & 64 & $64 \%$ \\
\hline Agree & $26-50$ & 24 & $24 \%$ \\
\hline Disagree & $1-25$ & 12 & $12 \%$ \\
\hline
\end{tabular}

Table 1 depicts that the frequency and percentage distribution that out of 100 nursing students $64 \%$ of nursing students having strongly agree opinion regarding clinical supervision, 24\% nursing students having agree opinion regarding clinical 


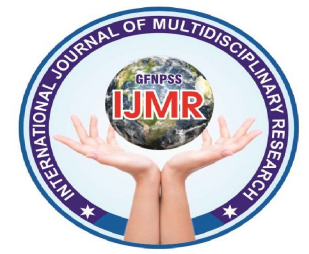

\section{Original Article}

supervision and $12 \%$ nursing students having disagree opinion regarding clinical supervision

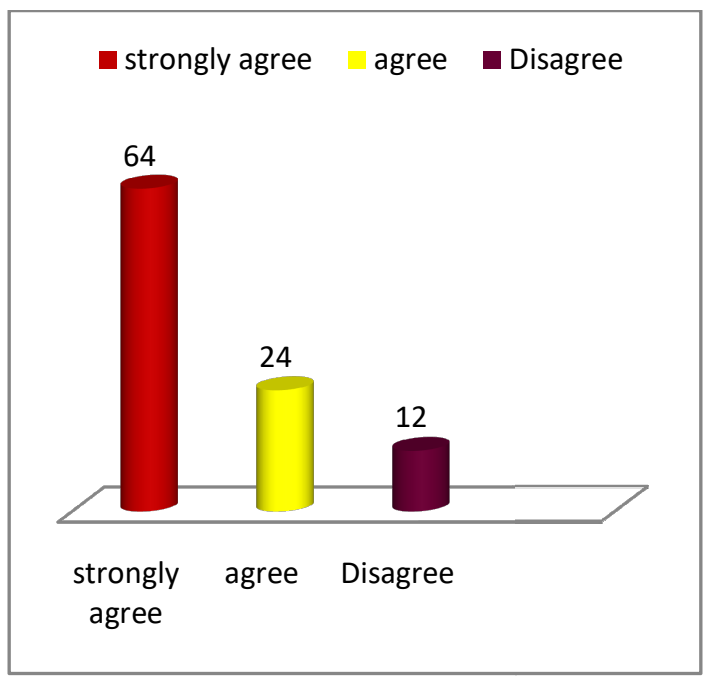

Bar graph showing frequency and percentage distribution of nursing students depending on their opinion.

Table 2: Mean and S.D. of nursing students depending upon their opinion regarding clinical supervision.

$\mathbf{N}=\mathbf{1 0 0}$

\begin{tabular}{|c|c|c|}
\hline Group & Mean & S.D \\
\hline $\begin{array}{c}\text { Nursing } \\
\text { Students }\end{array}$ & 51 & 17.5 \\
\hline
\end{tabular}

Association of opinion of nursing students with the demographic variable

There is no statically association between opinion and selected demographic variable. On analysis there was no statistically significant association between age, gender, class, duration of clinical experience, residence and number of ward you experienced

\section{DISCUSSION}

When affected supervision from nursing students was assessed that finding reveals the association of opinion and selected demographic variables like age gender year of experience etc. As evidenced by chi square it showed that as an overall there is no significant differences in means between the nursing students. This indicates that undergraduate students perception towards their supervisors are similar regardless of any demographic variables.

\section{CONCLUSION}

The present study concluded that nursing students have strongly agree regarding supervision of nursing students in clinical area.

RECOMMENDATIONS: On the basis of the findings of the study, following recommendations are made:

1. Similar studies can be done on a larger sample to generalize the finding.

2. Similar studies can be a conducted with an experimental research design having a control group.

3. An induction programmed at the institutions under study with peer and formal evaluation good benefit the newly appointed clinical supervisor 


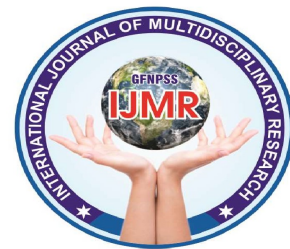

which is intended to prepare the new supervisor for their specific role.

\section{REFERENCES}

1. Bambling $M$, King R,Raue $P$, Schweitzer R,Lambert W. Clinical supervision: its influence on clients rated working alliance and clients symptom reduction in the brief treatment of major depression 2006;16(3):317-417.

2. Debra Rose wilson, ph.D,MSN, R.N., IBCLC, AHN-BC- Written by sara Lindberg on june 25, 2020.

3. Healthline: Medical information \& hea lth advicehttps://www.healthline.co m

4. Milne DL,Watkins CE. Defining and understanding clinical supervision:A functional approach .in: Watkin CE, Milne DL, editors. Wiley; 2014 p. 3-19

5. CASPChecklist.http://www.Caspuk. net/checklists 8 January 2018.

6. Gabieba Donough, Marianna van der Heever. Undergraduate nursing students' experience of clinical supervision; 12 Nov. 2018.
7. Stella Kamphinda and Evelyn B. Chilemba Clinical supervision and support: Perspectives of undergraduate nursing students on their clinical learning environment in Malawi;2019 May 23. doi:

10.4102/curationis.v42i1.1812.

8. K Teasdale, N Brocklehurst, N Thom Clinical Supervision and Support for Nurses: An Evaluation Study;J Adv Nurs. 2001 Jan;33(2):216-24.

9. Ingrid Bégat, Bodil Ellefsen, Elisabeth Severinsson Nurses' Satisfaction With Their Work Environment and the Outcomes of Clinical Nursing Supervision on Nurses' Experiences of Well-Being -- A Norwegian Study ;J Nurs Manag. 2005 May;13(3):221-30.

10. Leena Honkavuo Nursing Students' Perspective on a Caring Relationship in Clinical Supervision;Nurs Ethics. 2019 Sep 8;969733019871695. 